\title{
Comunicação
}

[Communication $]$

\section{Estimação por aproximação química dos teores de proteína indegradável insolúvel em detergente neutro em forragens tropicais}

[Estimation of undegradable neutral detergent insoluble protein in tropical forages by chemical approaching]

\author{
E. Detmann ${ }^{1}$, J.F.C. Silva ${ }^{2}$, R.C. Clipes ${ }^{2}$, L.T. Henriques ${ }^{1}$, S.C. Valadares Filho ${ }^{1}$, \\ A.C. Queiroz ${ }^{1}$, M.F. Paulino ${ }^{1}$ \\ ${ }^{1}$ Departamento de Zootecnia - UFV \\ Av. P.H. Rolfs, s/n \\ 36571-000 - Viçosa, MG \\ ${ }^{2}$ Universidade Estadual do Norte Fluminense - Campos dos Goytacazes, RJ
}

A proteína indegradável insolúvel em detergente neutro (PIIDN) constitui conceito analítico que busca aproximar-se do valor paramétrico da proteína indegradável da parede celular (Detmann et al., 2007), consistindo da avaliação da proteína bruta $(\mathrm{PB})$ residual do alimento após 240 horas de incubação ruminal in situ, seguida pelo tratamento da amostra com detergente neutro para remoção de debris microbianos (Clipes et al., 2006).

Desta forma, em função da busca de representatividade de um conceito biológico (proteína indegradável), ensaio biológico (incubação ruminal) é recomendado para sua estimação (Detmann et al., 2008b). Devido ao seu significado nutricional, a PIIDN tem sido sugerida como parâmetro para estimação da fração digestível da PB e, consequentemente, do teor de nutrientes digestíveis totais (NDT) em alimentos e dietas ofertados para ruminantes nos trópicos (Detmann et al., 2008a; 2008b). No entanto, devido ao longo tempo necessário para obtenção de estimativas ( 240 horas) e à necessidade de animais fistulados, sua estimação a partir de ensaios biológicos pode comprometer a praticidade de aplicação para obtenção laboratorial rápida de estimativas dos teores de NDT dos alimentos. Assim, o desenvolvimento de uma aproximação por métodos químicos, normalmente, mais rápidos, constitui alternativa para se contornar os entraves práticos do processo de estimação por vias biológicas.

Recebido em 22 de junho de 2009

Aceito em 3 de maio de 2010

E-mail: detmann@ufv.br

Apoio: CNPq e FAPEMIG (Programa Pesquisador Mineiro)
A proteína insolúvel em detergente ácido (PIDA) tem sido aplicada como parâmetro de predição da fração digestível da PB (Nutrient..., 2001). Contudo, a relevância biológica dos compostos insolúveis em detergente ácido é questionável (Van Soest, 1994; Detmann et al., 2006). Apesar disto, correlações moderadas são observadas entre a PIIDN e a PIDA em forragens tropicais (Clipes, 2007), o que permitiria, na ausência de parâmetro melhor correlacionado, e mesmo na presença de limitações biológicas conceituais, a utilização da PIDA como parâmetro preditor da PIIDN. Neste sentido, Clipes (2007) propôs equação de predição dos teores de PIIDN dada por:

$P I I D N=\left(1,1557+0,0255 \times P I D A^{2,3388}\right)^{2} \quad\left(\mathrm{~s}_{\mathrm{xy}}=0,2152\right) \quad(1) ;$ em que

PIIDN e PIDA são dados como percentual da matéria seca (MS).

Contudo, a equação (1) apresenta pequena inconsistência biológica para algumas situações, pois os teores de PIIDN serão sempre maiores ou iguais a $1,34 \%$ da MS. A PIIDN constitui fração ou parte da proteína insolúvel em detergente neutro (PIDN) (Henriques et al., 2007). Assim, alimentos com teores de PIDN inferiores a $1,34 \%$ da MS apresentarão teores estimados de PIIDN superiores à PIDN, o que caracteriza inconsistência biológica para a equação (1) nessas situações. 
Objetivou-se neste trabalho desenvolver modelo matemático com maior consistência biológica para predição dos teores de PIIDN a partir dos teores de PIDA em forragens tropicais.

O banco de dados foi constituído por amostras de gramíneas tropicais empregadas na alimentação de animais ruminantes, coletadas no município de Campos dos Goytacazes-RJ, durante o ano de 2002. As amostras foram obtidas na forma de forragem in natura, coletadas por corte a 15$30 \mathrm{~cm}$ do solo em parcelas de cultivo experimental (Acroceras macrum, Brachiaria purpurascens, Hemathria altissima, Setaria anceps, Pennisetum purpureum - $\mathrm{n}=399$ ); na forma de forragem in natura, coletada por simulação manual de pastejo (Pennisetum purpureum, Pannicum maximum - $\mathrm{n}=48$ ); na forma de forragem in natura, coletada como extrusa esofágica (Pennisetum purpureum, Pannicum maximum $-\mathrm{n}=48$ ) e na forma de feno (Acroceras macrum, Brachiaria purpurascens, Hemathria altissima, Setaria anceps $-\mathrm{n}=45$ ), totalizando 540 amostras.

As amostras foram secas sob ventilação forçada $\left(60^{\circ} \mathrm{C}\right)$ e processadas em moinho de facas $(2 \mathrm{~mm})$, sendo quantificados os teores de MS, de fibra em detergente neutro (FDN) e de fibra em detergente ácido (FDA) (Silva e Queiroz, 2002). A partir dos resíduos obtidos nas análises de FDN e FDA, foram analisados os teores de PIDN e PIDA, conforme recomendações de Licitra et al. (1996) (Tab. 1).

Os teores de PIIDN foram avaliados em adaptação aos procedimentos descritos por
Clipes et al. (2006). As amostras, acondicionadas em duplicatas em sacos de náilon com porosidade de $50 \mu \mathrm{m}$ e dimensões 3,5 x $5,0 \mathrm{~cm}$ na proporção de $25 \mathrm{mg}$ de $\mathrm{MS} / \mathrm{cm}^{2}$ de superfície, foram incubadas no rúmen de um bovino alimentado com dieta contendo alimento volumoso (feno de gramínea) e concentrado, na proporção de 70:30, com base na MS. Após 240 horas de incubação, os sacos foram retirados, lavados em água corrente até o total clareamento, submetidos à extração com detergente neutro (Silva e Queiroz, 2002), na proporção de $50 \mathrm{~mL} / \mathrm{saco}$, e lavados com água quente e acetona. Posteriormente, os sacos foram secos sequencialmente em estufa com ventilação forçada $\left(60^{\circ} \mathrm{C} / 72\right.$ horas) e estufa não ventilada (105\% hora), acondicionados em dessecador e pesados.

O resíduo obtido foi avaliado pelo método de Kjeldahl (Silva e Queiroz, 2002) para quantificação do teor de nitrogênio, o qual foi considerado como o teor de compostos nitrogenados indegradáveis no rúmen. $\mathrm{O}$ teor de nitrogênio obtido, depois de multiplicado pelo fator 6,25 e corrigido para a massa total da alíquota incubada, foi considerado estimativa da PIIDN (Tab. 1).

As avaliações estatísticas foram realizadas por intermédio do programa SAS utilizando-se os procedimentos UNIVARIATE, REG e NLIN (algoritmo de Gauss-Newton).

Tabela 1. Estatísticas descritivas para os teores (\% da matéria seca) de proteína insolúvel em detergente neutro (PIDN), proteína insolúvel em detergente ácido (PIDA) e proteína indegradável insolúvel em detergente neutro (PIIDN) e para a razão PIIDN/PIDN

\begin{tabular}{ccccc}
\hline \multirow{2}{*}{ Estatística } & \multicolumn{3}{c}{ Variável } \\
\cline { 2 - 5 } & PIDN & PIDA & PIIDN & PIIDN/PIDN \\
\hline Média & 6,08 & 1,98 & 1,76 & 0,3196 \\
Mediana & 5,25 & 2,03 & 1,68 & 0,2960 \\
Máximo & 14,10 & 4,04 & 4,29 & 0,8012 \\
Mínimo & 1,88 & 0,39 & 0,29 & 0,0886 \\
Desvio-padrão & 2,80 & 0,88 & 0,67 & 0,1234 \\
$\mathrm{n}$ & 540 & 540 & 540 & 540 \\
\hline
\end{tabular}


Após a inspeção gráfica das relações entre PIDN, PIDA e PIIDN, optou-se pela razão PIIDN/PIDN como variável dependente (Tab. 1), uma vez que os teores de PIIDN seriam preditos como fração da PIDN, evitando-se a inconsistência biológica discutida anteriormente. Desta forma, impor-se-ia a restrição:

$$
\text { PIIDN } \leq \text { PIDN }, \forall \text { PIDN }
$$

A inspeção gráfica da associação entre os teores de PIDA e a relação PIIDN/PIDN indicou associação exponencial, a qual foi representada pelo modelo:

$$
\begin{aligned}
& R=e^{-(0,8188+0,1676 P I D A)} \quad\left(\mathrm{s}_{\mathrm{xy}}=0,1140\right) \\
& \text { em que }
\end{aligned}
$$
$R=$ razão PIIDN/PIDN; e PIDA expresso em $\%$
da MS.

A relação entre compostos nitrogenados totais e indegradáveis associados à parede celular vegetal é extremamente variável (Henriques et al., 2007), dificultando, à luz do conhecimento atual, predição com alto nível de exatidão a partir de parâmetros químicos. Isto justifica a alta dispersão dos pares ordenados em torno da função ajustada (Fig. 1). Contudo, apesar da alta dispersão, percebe-se que a proposição exponencial (equação 3) acompanhou a tendência dos pares ordenados em função dos teores de PIDA nas forragens avaliadas.

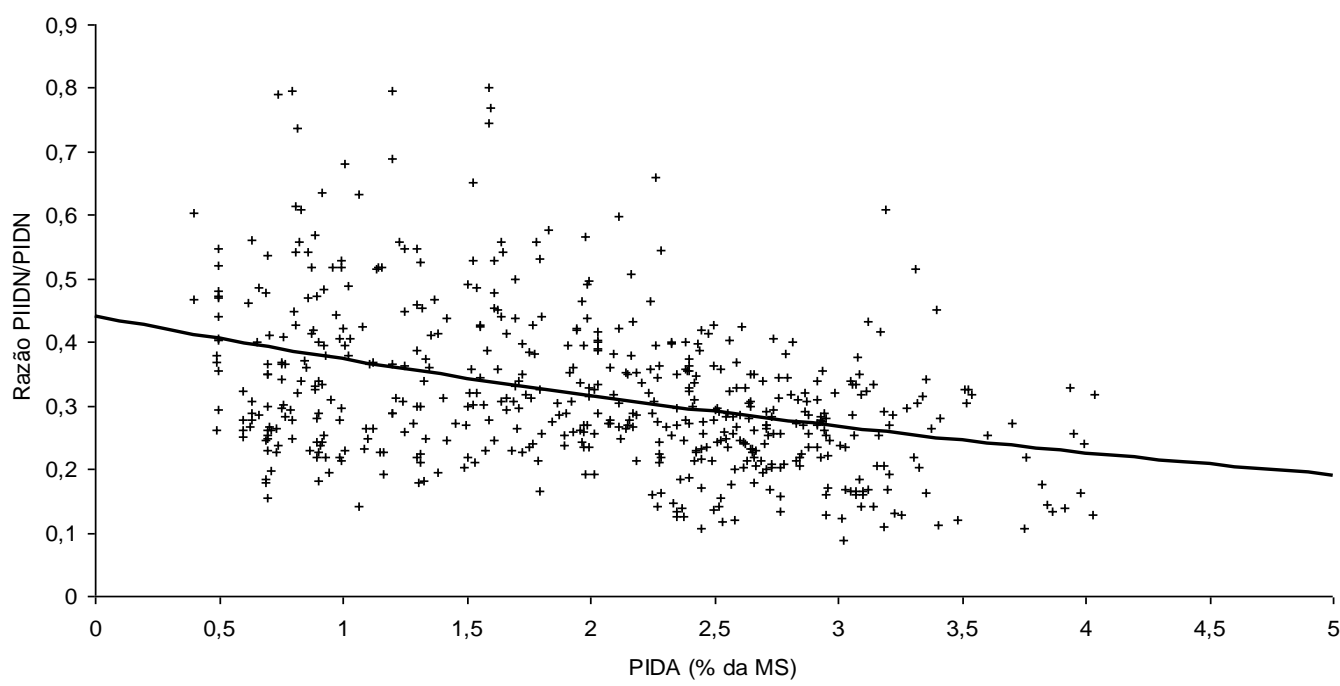

Figura 1. Relação entre os teores de proteína insolúvel em detergente ácido (PIDA) e a razão entre os teores de proteína indegradável insolúvel em detergente neutro (PIIDN) e proteína insolúvel em detergente neutro $(\mathrm{PIDN})(\mathrm{n}=540)$. A linha contínua corresponde à estimativa obtida via equação (3) $\left[R=e^{-(0,8188+0,1676 P I D A)} \quad\left(\mathrm{s}_{\mathrm{xy}}=0,1140\right)\right]$.

A partir da equação (3), os teores de PIIDN (\% da MS) em forragens tropicais podem ser preditos diretamente por:

$$
\begin{aligned}
& P I I D N=P I D N \times R \\
& P I I D N=P I D N \times e^{-(0,8188+0,1676 P I D A)}
\end{aligned}
$$

A relação entre valores preditos de PIIDN e observados de PIDA permitiu evidenciar que a restrição das estimativas observadas com a aplicação da equação (1) foi eliminada (Fig. 2), permitindo a obtenção de valores de PIIDN sempre inferiores aos valores de PIDN, o que é biologicamente consistente.
Ressalta-se que o ganho estatístico com o novo modelo foi considerado pequeno, o que é percebido pelo pequeno incremento na correlação entre PIDA (valores observados) e PIIDN (valores preditos) em comparação com o modelo proposto por Clipes (2007) (Fig. 2). Contudo, a retirada da limitação biológica deve ser vista como o verdadeiro incremento ao processo de predição propiciado pelo novo modelo - equação (4). 

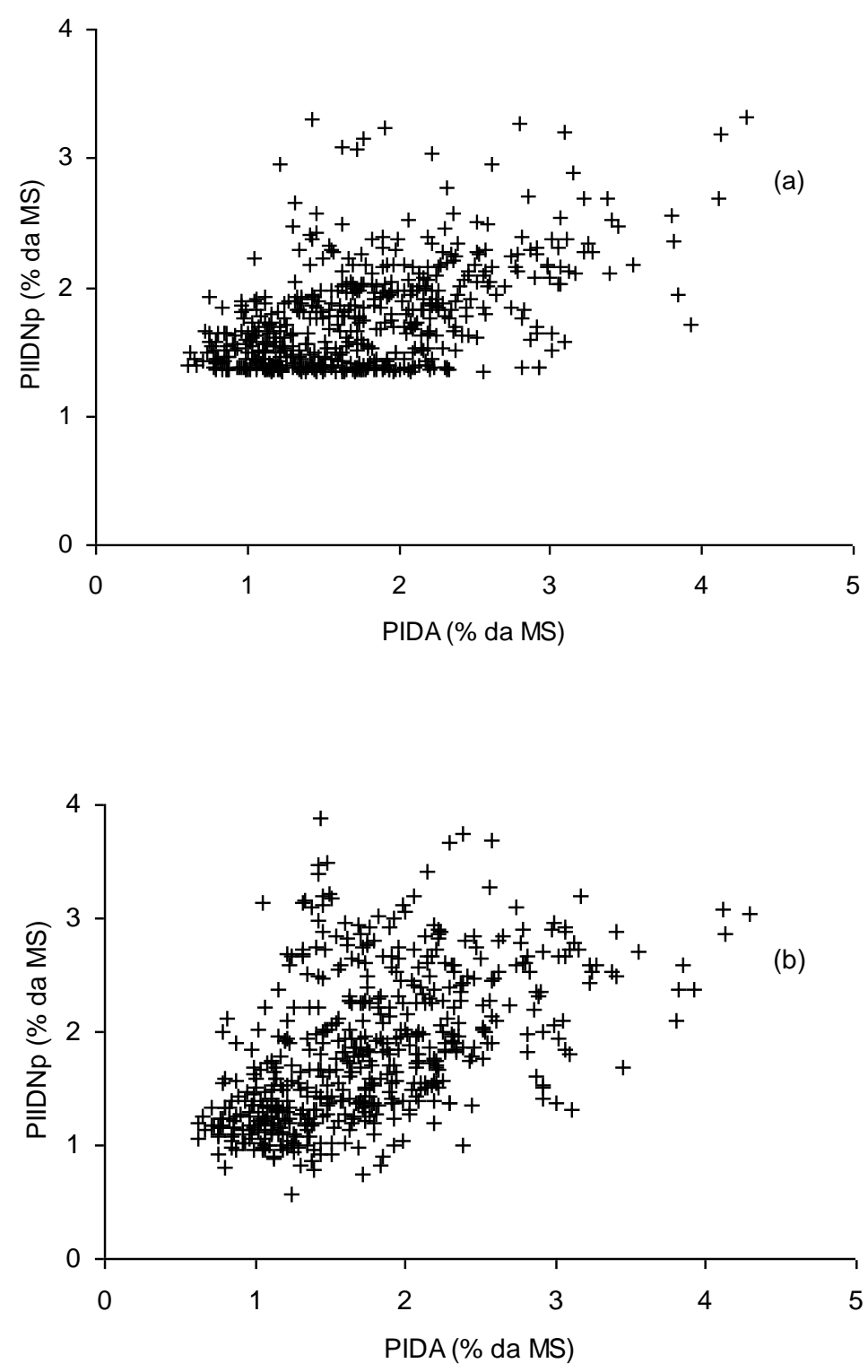

Figura 2. Comportamento descritivo para a relação entre os teores observados de proteína insolúvel em detergente ácido (PIDA) e os teores preditos de proteína indegradável insolúvel em detergente neutro (PIIDNp) [a: equação (1); Clipes, 2007; $r=0,5106$. b: equação (3b); $r=0,5115$ ].

O coeficiente de correlação moderado observado para o novo modelo $(\mathrm{r}=0,5115)$ indica que o processo de predição de um parâmetro biológico (PIIDN) a partir de uma característica unicamente química (PIDA) ainda apresenta restrições e as estimativas produzidas podem ser vistas com cautela em algumas situações. Contudo, na ausência de praticidade dos métodos biológicos vigentes para se acessar os teores de
PIIDN em forragens tropicais, a aproximação química pode constituir ferramenta útil em situações nas quais haja restrição na disponibilidade de animais fistulados e/ou necessidade de resultados com maior rapidez.

Palavras-chave: proteína insolúvel em detergente ácido, proteína digestível, degradação ruminal, degradação proteica 


\begin{abstract}
A mathematical model was developed to predict the content of undegradable neutral detergent insoluble protein (UNDIP) from chemical characteristics of tropical forages. This study was based on a biological limitation of a previous model, which restricts the UNDIP estimates to values equals or higher than $1.34 \%$ of dry matter. The databank was formed by 540 samples of tropical forages used in cattle feeding (fresh forage and hay). The ratio of UNDIP on neutral detergent insoluble protein (NDIP) was chosen as response variable and the acid detergent insoluble protein (ADIP) as independent variable. The mathematical model was found to be exponential, assuming the formula: $U N D I P=N D I P \times e^{-(0.8188+0.16764 D I P)}$, in which all values are expressed on dry matter basis. It was observed that biological limitation of the previous model was eliminated, even though a low statistical improvement was obtained. The prediction of a biological parameter (UNDIP) from a chemical characteristic (ADIP) still have some restrictions and the estimates should be applied with caution in some situations. The main application of the model described above is estimate UNDIP contents when biological methods are not available.
\end{abstract}

Keywords: acid detergent insoluble protein, digestible protein, rumen degradation, protein degradation

\section{REFERÊNCIAS BIBLIOGRÁFICAS}

CLIPES, R.C.; DETMANN, E.; COELHO DA SILVA, J.F. et al. Evaluation of acid detergent insoluble protein as an estimator of rumen nondegradable protein in tropical grass forages. Arq. Bras. Med. Vet. Zootec., v.58, p.694-697, 2006.

CLIPES, R.C. Degradação ruminal de compostos fibrosos e nitrogenados em gramíneas tropicais. 2007. 74f. Tese (Doutorado) Universidade Estadual do Norte Fluminense, Campos dos Goytacazes.

DETMANN, E.; PAULINO, M.F.; COELHO DA SILVA, J.F. et al. Digestibilidade dos compostos nitrogenados insolúveis em detergente ácido em bovinos manejados em pastagem de capim-braquiária. Rev. Bras. Zootec., v.35, p.1463-1468, 2006.

DETMANN, E.; MAGALHÃES, K.A.; VALADARES FILHO, S.C. et al. Desenvolvimento de um sub-modelo bicompartimental para estimação da fração digestível da proteína bruta em bovinos a partir da composição química dos alimentos. Rev. Bras. Zootec., v.37, p.2215-2221, 2008a.
DETMANN, E.; PAULINO, M.F.; VALADARES FILHO, S.C. Avaliação nutricional de alimentos ou dietas? Uma abordagem conceitual. In: SIMPÓSIO DE PRODUÇÃO DE GADO DE CORTE. 6., 2008. Viçosa. Anais... Viçosa: DZO-UFV, 2008b. p.2152 .

HENRIQUES, L.T.; DETMANN, E.; QUEIROZ, A.C. et al. Frações dos compostos nitrogenados associados à parede celular em forragens tropicais. Arq. Bras. Med. Vet. Zootec., v.59, p.258-263, 2007.

LICITRA, G.; HERNANDEZ, T.M.; VAN SOEST, P.J. Standardization of procedures for nitrogen fractionation of ruminant feeds. Anim. Feed Sci. Techn., v.57, p.347-358, 1996.

NUTRIENT requirements of dairy cattle. 7.ed. Washington: National Academy of Sciences, 2001. 381p.

SILVA, D.J.; QUEIROZ, A.C. Análise de Alimentos: métodos químicos e biológicos. 3.ed. Viçosa: UFV, 2002. 235p.

VAN SOEST, P.J. Nutritional ecology of the ruminant. 2.ed. Ithaca: Cornell University, 1994. 476p. 